\title{
Serum concentrations of LH and FSH in the healthy newborn
}

\author{
H Schmidt and H P Schwarz \\ University Children's Hospital, Dr von Haunersches Kinderspital, Lindwurmstr. 4, 80337 Munich, Germany \\ (Correspondence should be addressed to H Schmidt; Fax: +49-89-51604784)
}

\begin{abstract}
Objective: A sex difference in fetal and neonatal pituitary-gonadal function has been well documented. The aim of the following study was to determine sex differences and patterns of basal LH/FSH in the neonatal period.

Design: Peripheral venous blood was obtained from 164 healthy full term newborns (91 males, 73 females) for clinically indicated laboratory examinations.

Results: In male newborns, LH values were initially low (days 1-5), increased between days 6 and 10 , and reached maximum levels between days 16 and 20. Levels of FSH were initially low (days 1-5), increased between days 6 and 10 and reached maximum levels between days 11 and 15. In female newborns, LH levels were generally lower than in newborn boys; levels were initially low, then increased between days 11 and 15 and reached maximum levels at the end of the newborn period. FSH values were generally higher than in newborn boys; there were initially low values with a first peak between days 11 and 15 and a second peak between days 21 and 28 .

Conclusions: LH values in male newborns were higher and exceeded values in female newborns, whereas FSH values in female newborns exceeded male newborn values. Male newborns do not exhibit any peaks of LH and FSH activity, whereas female newborns exhibit two FSH peaks during this period.
\end{abstract}

European Journal of Endocrinology 143 213-215

\section{Introduction}

Normal function of the hypothalamic-pituitarygonadal axis is crucial for mammalian reproduction. Experimental evidence obtained in several species suggests that this axis is functional during fetal and neonatal life $(1,2)$. Cross-sectional studies of plasma gonadotrophin and sex steroid concentrations in human fetuses and newborns have lent support to this concept in humans $(2,3)$. However, there are at present few data on the dynamics of pituitary gonadotrophin secretion in humans before the age of 6 weeks (4). On the other hand, a sex difference in fetal pituitarygonadal function has been well documented $(2,5-7)$. It has been reported that transient activation of the pituitary-gonadal axis occurs, and sex differences in circulating gonadotrophin levels are present during the first few months of life and that there is a significant difference between term and preterm infants $(8,9)$. The aim of our study was to determine sex differences and patterns of basal luteinizing hormone (LH) and folliclestimulating hormone (FSH) in the first 28 days of life.

\section{Design}

From 164 healthy, full term neonates (91 males and 73 females), LH and FSH levels from day 1 to day 28 of life were determined. The newborns did not suffer severe distress. Blood was sampled for hemoglobin, bilirubin, glucose and other determinations as clinically indicated. The remainder of the blood was then used for $\mathrm{LH}$ and FSH determinations. It was confirmed in retrospect that the blood sampled was from healthy newborns. Blood was sampled from each neonate only once.

\section{Methods}

Peripheral venous blood was collected by venipuncture for clinically indicated analysis between 0800 and $1000 \mathrm{~h}$. Serum FSH and LH concentrations were assayed using a standard RIA method (Serono MAIA clone, Freiburg, Germany). In our laboratory the intraassay coefficient of variation for $\mathrm{LH}$ was $4.5 \%$ and $5.4 \%$ for FSH. The cross-reactivity of the LH assay was 3\% for human chorionic gonadotrophin. The minimum detectable levels of $\mathrm{LH}$ and $\mathrm{FSH}$ were $0.15 \mathrm{mIU} / \mathrm{ml}$ and $0.3 \mathrm{mIU} / \mathrm{ml}$ respectively. The sensitivity of the assay, i.e. the detection limit, was defined as the concentration of the LH or FSH equivalent to the mean c.p.m. of the zero standard plus 2 S.D., or roughly double the c.p.m. of the zero standard. The Mann-Whitney test was applied for comparison of LH and FSH values between columns 
Table 1 Pooled LH and FSH values (means \pm s.D.) from male newborns.

\begin{tabular}{lrcc}
\hline Age (days) & $\boldsymbol{n}$ & LH & FSH \\
\hline $1-5$ & 30 & $0.39 \pm 0.48$, median 0.20 & $0.96 \pm 0.60$, median 0.85 \\
$6-10$ & 15 & $2.31 \pm 2.29$, median 1.50 & $2.91 \pm 4.38$, median 1.40 \\
$11-15$ & 17 & $3.55 \pm 2.84$, median 2.90 & $3.71 \pm 2.69$, median 3.00 \\
$16-20$ & 14 & $4.13 \pm 2.76$, median 3.65 & $2.63 \pm 1.45$, median 2.15 \\
$21-25$ & 7 & $2.86 \pm 1.51$, median 2.70 & $2.50 \pm 1.51$, median 2.10 \\
$26-28$ & 8 & $2.22 \pm 2.37$, median 1.40 & $2.25 \pm 0.81$, median 2.40 \\
\hline
\end{tabular}

Table 2 Pooled $\mathrm{LH}$ and FSH values (means \pm S.D.) from female newborns.

\begin{tabular}{crcc}
\hline Age (days) & $\boldsymbol{n}$ & LH & FSH \\
\hline $1-5$ & 31 & $0.48 \pm 0.66$, median 0.20 & $2.00 \pm 1.37$, median 1.80 \\
$6-10$ & 17 & $0.45 \pm 0.33$, median 0.30 & $2.44 \pm 2.52$, median 1.40 \\
$11-15$ & 8 & $1.58 \pm 1.28$, median 1.60 & $8.16 \pm 4.27$, median 8.95 \\
$16-20$ & 6 & $1.03 \pm 1.39$, median 0.35 & $1.62 \pm 1.05$, median 1.90 \\
$21-25$ & 3 & $0.46 \pm 0.25$, median 0.50 & $7.07 \pm 5.92$, median 3.90 \\
$26-28$ & 8 & $2.75 \pm 2.39$, median 2.80 & $9.74 \pm 9.89$, median 6.15 \\
\hline
\end{tabular}

and for comparison of gonadotrophins between newborn males and females.

\section{Results}

Blood was collected from 164 healthy newborns (91 male and 73 female newborns) for the determination of LH and FSH values. Pooled data (mean \pm S.D. and median) from newborn males and females are shown in Tables 1 and 2. Differences in $\mathrm{LH}$ values between males and females (measured between days 16 and 20 and 21 and 25) were statistically significant, with male values clearly exceeding female values. However, FSH concentrations were significantly higher in females on days $1-5,11-15$ and $26-28$ (Table 3 ).

In male newborns LH values exceeded FSH values whereas in female newborns FSH values were always greater. In male newborns LH values were higher, and FSH values lower, than in female newborns. The number of peaks for FSH during the neonatal period is higher in females than in males.

Table 3 Mann-Whitney test for comparison of pooled male and female LH and FSH values.

\begin{tabular}{lll}
\hline Age (days) & \multicolumn{1}{c}{ LH } & \multicolumn{1}{c}{ FSH } \\
\hline $1-5$ & $\mathrm{p} 0.4086(\mathrm{~ns})$ & 0.0011 \\
$6-10$ & $\mathrm{p} 0.0910(\mathrm{~ns})$ & $0.9103(\mathrm{~ns})$ \\
$11-15$ & $\mathrm{p} 0.0756(\mathrm{~ns})$ & 0.0183 \\
$16-20$ & $\mathrm{p} 0.0057$ & $0.3119(\mathrm{~ns})$ \\
$21-25$ & $\mathrm{p} 0.0167$ & $0.0667(\mathrm{~ns})$ \\
$26-28$ & $\mathrm{p} 0.7209(\mathrm{~ns})$ & 0.0047 \\
\hline
\end{tabular}

ns, not significant.

\section{Discussion}

Although there are reports on neonatal serum gonadotrophin and sex steroid levels, there are few sequential studies (8). It has been shown that male newborns have higher LH values than female newborns (10). It has also clearly been established that premature newborns have substantially higher neonatal gonadotrophin levels compared with mature newborns (11). Although the changes in LH and FSH concentrations could be coincidental, this is clearly the situation in clinical conditions when blood is sampled at random times. Our results demonstrate a wide inter-individual variation for LH and FSH values in male and female newborns but clearly show that $\mathrm{LH}$ values dominate in the male newborn and FSH values dominate in the female newborn. Mean LH values show a stable elevation in both female and male newborns, whereas FSH demonstrates two clear peaks in the females. The sample size was small and there were days when few data were collected, so the results of our study must be interpreted with caution. A large variation in $\mathrm{LH}$ and FSH concentration is evident and can be mostly explained by the pulsatility of gonadotrophin secretion at this age and again in adolescence and aduldhood (12). Nevertheless, defining the range of the mean values and the trends for neonatal gonadotrophin secretion could be helpful in the evaluation of intersexual states, gonadotrophin deficiency or gonadal dysgenesis.

\section{Acknowledgements}

Selected data have been presented previously as a poster at 33rd Annual Meeting of European Society for Paediatric Endocrinology, 22-25 June 1994, Maastricht, The Netherlands. 


\section{References}

1 Grumbach MM \& Kaplan SL. The neuroendocrinology of human puberty: an ontogenetic perspective. In Control of the Onset of Puberty, pp 1-68. Eds MM Grumbach, PC Sizonenko \& M Aubert. Baltimore: Williams \& Wilkins, 1990.

2 Kaplan SL \& Grumbach MM. The ontogenesis of human foetal hormones. II. Luteinizing hormone (LH) and follicle stimulating hormone (FSH). Acta Endocrinologica 1976 808-829.

3 Forest MG \& Cathiard AM. Pattern of plasma testosterone and delta 4-androstenedione in normal newborns: evidence for testicular activity at birth. Journal of Clinical Endocrinology and Metabolism 197541 977-980.

4 Waldhauser F, Weisenbacher G, Frisch H \& Pollak A. Pulsatile secretion of gonadotropins in early infancy. European Journal of Pediatrics $198113771-74$.

5 Reyes FI, Boroditsky RS, Winter JSD \& Faiman C. Studies on human sexual development. II. Fetal and maternal serum gonadotropin and sex steroid concentrations. Journal of Clinical Endocrinology and Metabolism 197438 612-617.

6 Siler-Khodr TM \& Khodr GS. Studies in human fetal endocrinology. II. LH and FSH content and concentration in the pituitary. Obstetrics and Gynecology 198056 176-181.

7 Takagi S, Yoshida T, Tsubata K, Ozaki H, Fujii T K, Nomura Y \& Sawada M. Sex differences in fetal gonadotropins and androgens. Journal of Steroid Biochemistry 19778 609-620.
8 Winter JSD, Faiman C, Hobson WC, Prasad AV \& Reyes FI. Pituitary-gonadal relations in infancy. I. Patterns of serum gonadotropin concentrations from birth to four years of age in man and chimpanzee. Journal of Clinical Endocrinology and Metabolism 197540 545-551.

9 Shinkawa O, Furuhashi N, Fukaya T, Suzuki M, Kono H \& Tachibana Y. Changes of serum gonadotropin levels and sex differences in premature and mature infants during neonatal life. Journal of Clinical Endocrinology and Metabolism 198356 1327-1331.

10 Corbier P, Dehennin L, Castanier M, Mebazaa A, Edwards DA \& Roffi J. Sex differences in serum luteinizing hormone and testosterone in the human neonate during the first few hours after birth. Journal of Clinical Endocrinology and Metabolism 199071 1344-1348.

11 Heinrichs C, Bourdoux P, Saussez C, Vis HL \& Bourguignon JP. Blood spot follicle-stimulating hormone during early postnatal life in normal girls and Turner's syndrome. Journal of Clinical Endocrinology and Metabolism 199478 978-981.

12 de Zegher F, Devlieger H \& Veldhuis JD. Pulsatile and sexually dimorphic secretion of luteinizing hormone in the human infant on the day of birth. Pediatric Research 199232 605-607.

Received 29 January 1999

Accepted 30 March 2000 